УДК: $339.13+339.97+341$

JEL D41, K214 L10,11,12,40,49

ISSN: 2542-0259

(c) Российское конкурентное право

и экономика, 2020

\section{Пандемия COVID-19 как вызов для экономической конкуренции (аналитический обзор мер оперативного реагирования антимонопольных регуляторов весной 2020 года)}

Князева И.В.,

Сибирский институт

управления - филиал РАНХиГС, г. Новосибирск

\section{Аннотация}

В данной статье автором представлены оперативное обобщение и анализ наиболее важных решений, принимаемых конкурентными ведомствами в краткосрочном периоде пандемии COVID-19 (март-май 2020) и направленных на обеспечение функционирования рынков и поддержание конкуренции, а также экспертные мнения некоторых аналитиков по фактам принимаемых решений. Изложены основные подходы, которые представлены на онлайн-площадках Организации экономического сотрудничества и развития, Европейской комиссии, сайте CONCURRENCES: Antitrust Publication \& Events ${ }^{1}$, а также материалы ФАС России по принятию оперативных мер противодействия COVID-19.

Ключевые слова: конкуренция, конкурентная политика, экономический кризис, COVID-19, фиаско рынка, картель, согласованная политика конкурентов, государственная помощь, ценовые злоупотребления.

\title{
COVID-19 pandemic as the call for the economic competition (The state- of-the-art review of measures of rapid response of antimonopoly regulators in the spring of 2020)
}

Irina V. Knyazeva,

Siberian Institute of Management Russian Presidential Academy of National Economy and Public Administration

\section{Annotation}

In this article, the author presents an operational summary and analysis of the most important decisions made by competition agencies in the short-term period of the COVID-19 pandemic (march-may 2020) and aimed at ensuring the functioning of markets and maintaining competition, as well as expert opinions of some analysts on the facts of the decisions made. The main approaches that are presented on the on-line platforms of the Organization for economic cooperation and development, the European Commission, the site CONCURRENCES: Antitrust Publication \& Events, as well as materials of the FAS of Russia on taking operational measures to counter COVID-19 are described.

Keywords: competition, competitive policy, economic crisis, COVID-19, market fiasco, cartel, coordinated competitor policy, state aid, price abuse.

\section{Введение}

о время экономических кризисов или в условиях применения санкционных мер перед законодателями, правительствами и конкурентными ведомствами возникает вопрос о том, должны ли правоприменители быть более лояльными в при-

\footnotetext{
https://www.oecd.org/competition/competition-policy-responses-to-covid-19.htm (Дата обращения: 10.05.2020); https://www.concurrences.com/en/review/issues/no-2-2020/on-topic/competition-law-andhealth-crisis-en (Дата обращения: 10.05.2020).
} 
Пандемия COVID-19 как вызов для экономической конкуренции...

менении конкурентного законодательства по отношению к частным или публичным ограничениям конкуренции.

Официальные сайты Секретариата Конференции ООН по торговле и развитию (ЮНКТАД), Генеральной дирекции по конкуренции Еврокомиссии, Организации экономического сотрудничества и развития (ОЭСР), Международной конкурентной сети (ICN) ${ }^{2}$ стали активной дискуссионной площадкой обсуждения вопросов оперативной адаптации деятельности антимонопольных органов к текущим процессам разбалансированного функционирования рынков и блокировки экономической жизни.

Профессор экономики и председатель Комитета ОЭСР по конкуренции Фредерик Жанни подготовил несколько важных публикаций (март-май 2020 г.3), посвященных оперативному реагированию конкурентных ведомств на рыночную ситуацию, всестороннему анализу конкурентных отношений в условиях глубокой экономической депрессии, возможности и границам допустимости, а равно целесообразности ослабления норм и придания мягкой силы принципам конкурентного законодательства - от политики превентивного сдерживания цен и контроля за ними до разрешения в исключительных случаях согласованной политики в отношении некоторых рынков и выработки границ государственной помощи.

В этих условиях Тереза Морейра, руководитель подразделения ЮНКТАД по конкуренции и защите потребителей, в официальном заявлении, опубликованном на сайте, обратила внимание, что «при нормальных обстоятельствах конкуренция на рынках необходима для удержания цен на низком уровне, но с кризисом COVID-19, разрушающим рынки во всем мире, сотрудничество между конкурентными ведомствами, бизнесом и властью стало приоритетным. Многие конкурентные ведомства корректируют применение законов о конкуренции для реализации важной задачи - служение интересам общества во время кризиса» ${ }^{4}$ [1].

В заявлении руководителя ФАС России Игоря Юрьевича Артемьева международному конкурентному сообществу по COVID-19 выделена значительная роль ФАС России как «гаранта соблюдения антимонопольного законодательства, защищающего экономическую структуру не только рынков, оказавшихся в сложной ситуации во время пандемии, но и важного института, разраба-

2 https://www.oecd.org/competition/competition-policy-responsesto-covid-19.htm; https://ec.europa.eu/competition/index_en.html; https://www.internationalcompetitionnetwork.org/wp-content/ uploads/2020/04/SG-Covid19Statement- (Дата обращения: 10.05.2020)

3 Frédéric Jenny (Professor of Economics, ESSEC Business School, Cergy). Competition law and health crisis-04 May2020. https:// www.concurrences.com/en/review/issues/no-2-2020/on-topic/ competition-law-and-health-crisis-en (Дата обращения: 12.05.2020).

4 Statement of Teresa Moreira. Defending competition in the markets during COVID-19. UNCTAD, 08 April 2020 https://unctad.org/en/ pages/newsdetails.aspx?OriginalVersionlD=2325 (Дата обращения: 10.05.2020). тывающего меры, позволяющие менее болезненно восстанавливать экономику в условиях конкуренции, являющейся основой успешного экономического развития. Восстановление с наименьшими потерями предполагает обеспечение взвешенной политики между продвижением бизнеса, особенно среднего и малого, и помощью потребителям и гражданам, так как наблюдается рост числа антиконкурентных практик, случаев злоупотребления доминирующим положением и картелей. Контролируя ситуацию сегодня, мы, насколько это возможно, обеспечиваем более стабильное экономическое развитие страны в будущем» ${ }^{5}$.

В период пандемии и, главное, после нее в условиях масштабного кризиса и сложного восстановления экономической жизни необходимы обмен мнениями и идеями среди профессионального сообщества, обсуждение опыта и лучших практик антимонопольного реагирования, направленных на восстановление деловой активности.

В ходе совещания ЮНКТАД (12 мая) в формате видеоконференцсвязи замглавы ФАС А.Г. Цыганов выступил с предложением по включению в повестку дня ряда предстоящих мероприятий ЮНКТАД и вопросов ОЭСР, касающихся совместной роли конкурентных ведомств в использовании механизмов «мягкой силы» для стабилизации ситуации на рынках, приоритетов конкурентной политики в период выхода из кризиса. Им выделено, что «формирование глобального ответа конкурентных ведомств на пандемию требует консолидации усилий для наиболее быстрого реагирования и устранения негативных последствий в будущем»

\section{Фиаско рынка в период экзогенного шока COVID-19}

В краткосрочный период (март-май 2020 г.) основной проблемой, с которой пришлось столкнуться всем участникам рынка, стали разрывы производственно-сбытовых продуктовых цепочек, приостановка функционирования значительного количества рынков, особенно сервисных, прекращение транспортных международных коммуникаций.

Настоящий кризис, связанный с COVID-19, привел в первую очередь к перекрытию каналов поставок (главным образом из Китая), а во вторую - к обнулению запасов или жесткому дефициту на рынках, причем не только в отношении тех товаров, которые непосредственно предназначены для борьбы с инфекцией, но и применительно к гораздо более широким и разнообразным товарным группам (например, к дефициту чеснока на российском рынке).

5 Statement of Igor Artemiev, Head of the FAS Russia, to the international competition community on COVID-19. http://en.fas. gov.ru/press-center/news/detail.html?id=54878 (Дата обращения: 13.05.20200).

6 Андрей Цыганов. Пандемия - новый вызов для всех конкурентных ведомств мира. https://fas.gov.ru/news/29781 (Дата обращения: 15.05.2020).

Федеральная антимонопольная служба 
Одновременно падение спроса на большинство сервисов, за исключением доставки еды, из-за жесткого блокирования физического пребывания и доступа людей, сопровождалось в течение месяца ростом цен на товары кризисной повестки (маски, перчатки, аппараты ИВЛ, некоторые медпрепараты) и навязыванием невыгодных условий договора и иных ограничительных деловых практик.

Для субъектов малого и среднего предпринимательства сервисных отраслей, а также у авиационных компаний и бизнеса сферы гостеприимства наступил управленческий кризис, сопровождающийся невозможностью оплачивать труд сотрудников, дефицитом ликвидности, временным прекращением деятельности с неясными перспективами выхода из локдауна.

Европейская комиссия 8 апреля 2020 г. на официальном сайте разместила Временные рамочные рекомендации, в которых содержатся указания относительно возможных соглашений между конкурентами, а также предоставления государственной помощи, которые соответствуют нормам законодательства о конкуренции и допустимы во время пандемии COVID-197.

Президент Европейской комиссии, комиссар по конкуренции ЕС Маргрет Вестагер в связи с этим заявила: «Мы должны обеспечить достаточный запас важнейших фармацевтических препаратов и предметов медицины, необходимых для лечения пациентов с коронавирусом. Чтобы избежать риска нехватки основных и дефицитных продуктов и услуг из-за роста спроса, вызванного пандемией, необходимо, чтобы предприятия сотрудничали и делали это в соответствии с европейскими правилами конкуренции».

Такие активные и оперативные действия со стороны международных организаций поставили перед учеными и правоприменителями важный вопрос - какой должна быть роль антимонопольных органов во время кризиса?

П. М. Хорна в своем докладе показывает, что «антимонопольным органам всего мира пришлось столкнуться с трудным выбором. Должны ли они проявлять гибкость в правоприменении с учетом необычайно деструктивных ситуаций на ряде рынков или они должны твердо придерживаться своих принципов независимо от текущих обстоятельств? Если необходимы корректировки, то какие ожидаются последствия?»9.

7 Antitrust rules and coronavirus. https://ec.europa.eu/ competition/antitrust/coronavirus.html https://eur-lex.europa. eu/legal-content/en/TXT/?uri=uriserv:OJ.CI.2020.116.01.0007.01. FRAQtoc=0J:C:2020:116I:TOC (Дата обращения: 12.05.2020).

8 Antitrust: Commission provides guidance on allowing limited cooperation among businesses, especially for critical hospital medicines during the coronavirus outbreak -8 April 202-0Brussels. https://ec.europa.eu/commission/presscorner/ detail/en/IP_20_618 (Дата обращения: 10.05.2020).

9 Horna P.M. A global overview of the impact of COVID-19 on competition policies in key sectors // Competition law and health crisis. On-Topic I Concurrences $\mathrm{N}^{\circ} 2$ 2-2020: www.concurrences.com (Дата обращения: 12.05.2020).
Основные решения, предпринятые антимонопольными органами в период кризиса COVID-19

Международные институты в области защиты конкуренции и большинство антимонопольных органов опубликовали заявления или руководящие принципы по обеспечению соблюдения правил конкуренции с начала кризисного периода. В Российской Федерации такое заявление от имени руководителя ФАС России было официально опубликовано 17 апреля 2020 г. ${ }^{10}$

В рамочном формате все эти заявления содержат четкий сигнал о том, что антимонопольные органы не будут мириться с поведением фирм, стратегически использующих оправдание экономического кризиса для сознательной реализации антиконкурентных методов - установления хищнических или монопольно-высоких цен, злоупотребления рыночной властью, нарушения порядка ценообразования со стороны компаний, занимающих доминирующее положение, или путем заключения картельного соглашения.

Соответственно, все регуляторы подтвердили, что основополагающие принципы конкуренции остаются актуальными, особенно при злостных нарушениях, имеющих характер монополистической деятельности.

\section{Реакция на ценовые злоупотребления}

Федеральная торговая комиссия и Министерство юстиции США традиционно не поддерживают принятие мер, предупреждающих и не позволяющих значительно повышать («взвинчивать») цены, обоснованно полагая, что рост цен при дефиците товара является естественным и кратковременным. Вместе с тем в большинстве штатов существуют законы, предупреждающие хищническое ценообразование и недобросовестное завышение цен в чрезвычайных условиях. Поэтому, например, важной мерой борьбы с хищническим ценообразованием стало направление прокурорами большинства штатов писем с предупреждениями крупнейшим электронным торговым площадкам о недопущении чрезмерного роста цен на социально значимые товары в условиях кризиса"11.

В ЕС трудности применения положений закона о конкуренции в отношении ценовых злоупотреблений доминирующим положением не ограничили конкурентные ведомства многих европейских стран в возбуждении расследований, касающихся завышенных цен. В Италии рассматривались дела в отношении дезинфицирующих средств для рук и одноразовых масок, в Польше в отношении поставок средств индивидуальной защиты

10 Statement of Igor Artemiev, Head of the FAS Russia, to the international competition community on COVID-19. http://en.fas. gov.ru/press-center/news/detail.html?id=54878 (Дата обращения: 13.05.2020)

11 Price-Gouging-Letters-3.25.20. https://ago.vermont.gov/wpcontent/uploads/2020/03/Price-Gouging-Letters-3.25.20.pdf (Дата обращения: 17.05.2020). 
Пандемия COVID-19 как вызов для экономической конкуренции...

для больниц ${ }^{12}$. Конкурентное ведомство Франции создало сеть экстренного мониторинга цен в условиях расширяющейся эпидемии COVID-19.

В заявлении, опубликованном на официальном сайте СМА (антимонопольный орган Великобритании), отмечено, что ведомством будут оцениваться условия, характеризующие целесообразность рекомендации правительству принятия им прямых мер по регулированию тарифов, цен, арендной платы и др. ${ }^{13}$

В Южной Африке Комиссия по конкуренции (SACC) 19 марта 2020 г. ввела новые правила для решения конкретных проблем конкуренции в области ценообразования и поставок основных продуктов в связи с пандемией коронавируса ${ }^{14}$.

ФАС России мониторинг и постоянный контроль за ценами осуществляет в постоянном режиме с середины марта. Под ценовой контроль и проверку попали цены на услуги мобильной связи в период перевода сотрудников на дистанционную работу, медицинские маски, социально значимые продукты как в ретейле, так и в магазинах онлайн, товары медицинского ассортимента, лимоны и имбирь, оптовый газ для потребителей и др. В случае выявленных значительных ценовых колебаний принимаются различные решения - от предупреждений и обсуждений вопросов с участниками рынка до возбуждения дел и принятия мер прокурорского реагирования ${ }^{15}$.

В выступлении 27 марта 2020 г. руководитель ФАС России И. Ю. Артемьев отметил, что «ФАС России, находясь в авангарде борьбы с коронавирусом, ежедневно отслеживает ценовую ситуацию на рынках товаров первой необходимости и на рынках, пострадавших от пандемии, следит за отсутствием дефицита товаров и принимает меры по таким важным социальным товарам, как лекарства, медицинские изделия и продукты питания. Важное внимание уделяется вопросам контроля за недопустимостью злоупотреблений и картелей, а также фактов недобросовестной конкуренции и рекламы» ${ }^{16}$.

0 согласованной позиции от 3 апреля 2020 г. Минфина России, МЧС России, ФАС России об осуществлении за-

12 Frédéric Jenny. Competition law and health crisis-04 May 2020 //Competition law and health crisis. On-Topic - Concurrences N²-2020: www.concurrences.com (Дата обращения: 17.05.2020).

13 Statement of Lord Tyrie chairman of the CMA 20 March 2020: Www.gov.uk/guidance/deferral-of-vat-payments-due-tocoronavirus-covid-19 (Дата обращения: 10.05.2020).

14 Mark Griffiths. South Africa: Comprehensive package of antitrust measures adopted in response to Covid-19 pandemic // Competition law and health crisis. On-Topic - Concurrences $N^{\circ} 2-2020$ : www.concurrences.com (Дата обращения: 12.05.2020).

15 Меры ФАС России в связи с пандемией COVID-19. https://fas.gov. ru/pages/mery-v-svjazi-s-pandemiej-covid-2019 (Дата обращения: 13.05.2020).

16 Глава ФАС России Игорь Артемьев о ситуации на рынке лекарственных препаратов и медизделий: Брифинг, состоявшийся в пресс-центре Правительства Российской Федерации. https://fas. gov.ru/news/29560 https://fas.gov.ru/news/29619 (Дата обращения: 13.05.2020). купок товаров, работ и услуг для обеспечения государственных и муниципальных нужд в связи с распространением COVID-19 было объявлено достаточно оперативно и своевременно. Заместитель руководителя ФАС России М.Я. Евраев отметил: в данном документе закреплен факт того, что пандемия является обстоятельством непреодолимой силы и эту ситуацию необходимо учитывать при рассмотрении закупок товаров, работ и услуг, направленных на профилактику, предупреждение и ликвидацию последствий распространения COVID-19, осуществляемых у единственного поставщика, при условии наличия причинно-следственной связи цели и предмета такой закупки ${ }^{17}$.

В выступлениях начальника Управления по борьбе с картелями ФАС России А.П. Тенишева отмечалось, что ни в каком виде и ни под каким окрасом картели не допустимы: «...хочу призвать сельхозпроизводителей, переработчиков и розничных продавцов взвешенно подходить к каждому из этапов ценообразования и принимать только экономически обоснованные решения. Беспочвенные заявления о повышении цен, которые могут привести к нарушению антимонопольного законодательства, особенно на фоне пандемии, абсолютно недопустимы» ${ }^{18}$.

\section{Два подхода к контролю за горизонтальными соглашениями}

По мнению председателя комитета ОЭСР по конкуренции Фредерика Жанни, «серьезная проблема конкурентных ведомств в период кризиса из-за пандемии COVID-19 связана с тем, что компании могут стремиться или должны координировать свои действия, чтобы уменьшить нехватку основных продуктов или услуг, необходимых для ограничения распространения вируса или нахождения вакцины против него. Антимонопольные органы находятся под некоторым давлением, чтобы разрешить такую горизонтальную координацию или сотрудничество, что представляется желательным, по крайней мере, с точки зрения общественных интересов» ${ }^{19}$.

23 марта 2020 г. Европейская конкурентная сеть (ECN) опубликовала совместное заявление ${ }^{20}$, в котором высказала понимание того факта, что сложившаяся чрезвычайная ситуация может вызвать необходимость сотрудничества компаний с целью обеспечения поставок

17 https://fas.gov.ru/ckeditor_assets/attachments/1102/sovmestnoe_ pismo_mf_mchs_fas_pdf.pdf (Дата обращения: 17.05.2020).

18 Цены на подсолнечное масло под контролем. https://fas.gov.ru/ news/29765 (Дата обращения:13.05.2020).

19 Frédéric Jenny. Competition law and health crisis-04 May 2020 // Competition law and health crisis. On-Topic - Concurrences N²-2020: www.concurrences.com (Дата обращения: 12.05.2020).

20 Antitrust: Commission provides guidance on allowing limited cooperation among businesses, especially for critical hospital medicines during the coronavirus outbreak - 8 April 202-0Brussels (Дата обращения: 10.05.2020). 
и справедливого распределения дефицитных продуктов среди всех потребителей.

24 марта 2020 г. Федеральная торговая комиссия и Антимонопольное управление Министерства юстиции США опубликовали совместное заявление, в котором отметили, что «медицинские учреждения, нуждающиеся в координации предоставления ресурсов и услуг, могут осуществлять данную деятельность. То же касается и иных предприятий, которые могут временно нуждаться в объединении производственных, распределительных или сервисных сетей для облегчения производства и распределения поставок, связанных с COVID-19»²1.

В Российской Федерации до настоящего времени не было официальных публичных заявлений, касающихся поддержки и допустимости согласованной политики конкурентов на стратегически важных рынках в условиях пандемии. В период кризиса особую роль стали играть меры по адвокатированию конкуренции и распространению информации о деятельности ФАС России. Неоднократные выступления и предупреждения со стороны руководителей антимонопольного органа и его территориальных управлений, постоянный ценовой мониторинг, высокие риски подвергнуться проверке антимонопольного органа не позволили ценам «разгуляться» даже в условиях макроэкономической нестабильности и сильной волатильности курса рубля. Ажиотажный спрос на продукты питания и ряд других товаров в розничных сетях удалось преодолеть всего за 2-3 дня.

\section{Государственная помощь - быстрая реакция и пределы допустимости}

Режим государственной помощи, оперативно реализуемый правительствами стран со сложной эпидемиологической обстановкой для преодоления кризиса COVID-19, представляет область важных социально-экономических и политических решений, направленных на поддержку коммерческих фирм.

Европейская комиссия 19 марта 2020 г., имея опыт выработанных практик в период финансового кризиса 2008-2010 гг., быстро отреагировала на принимаемые государствами решения. Вопросы национальной государственной поддержки разрабатывались странами оперативно - принимался комплекс мер по прямой финансовой поддержке субъектов малого предпринимательства, широкий спектр налоговых каникул, субсидиарной государственной ответственности за предоставляемые кредиты под нулевые процентные ставки. Комиссия ЕС утвердила по состоянию на последнюю неделю апреля 2020 г. 1,9 трлн евро мер государственной помощи

21 Federal Trade Commission and Justice Department Announce Expedited Antitrust Procedure and Guidance for Coronavirus Public Health Efforts. https://www.ftc.gov/news-events/pressreleases/2020/03/ftc-doj-announce-expedited-antitrust-procedure; Crane D. A. Antitrust during (and especially after) a global pandemic (Дата обращения: 10.05.2020). посредством 95 решений, охватывающих 26 государствчленов и Великобританию22.

Важно отметить, что ФАС России достаточно оперативно отреагировала на кризисные вызовы и предприняла ряд действий, позволяющих снять административную нагрузку на бизнес и сформировать комплекс поддерживающих институциональных мер в дополнение к тем, которые объявили Президент и Правительство Российской Федерации ${ }^{23}$.

К ним можно отнести объявленные ФАС России предоставляемые отсрочки и рассрочки по уплате наложенных штрафов для временного облегчения финансового обременения предпринимателей, предложения о временной заморозке индексации оптовых цен на газ для населения, подходы при рассмотрении жалоб на госзакупки и закупки госкомпаний, возбуждении дел об административных правонарушениях ${ }^{24}$.

Таким образом, авторское мнение сопряжено с пониманием того факта, что государственная помощь, безусловно, отложит на неопределенный период времени уход с рынка тех компаний, которые накапливали за предыдущие годы груз неэффективности из-за коммерческих, финансовых и управленческих ошибок, но вместе с тем создаст условия для социальной и психологической стабильности в период жесткой изоляции граждан, здоровье и жизнь которых являются основой развития человеческого капитала и надеждой на нормальное восстановление экономики, спроса и, как следствие, благосостояние потребителей и благополучие граждан.

В среднесрочной перспективе - в течение следующих двух-трех лет - экономики всех стран, скорее всего, будут находиться в депрессивном состоянии, с риском большого числа банкротств предприятий, которые либо непосредственно пострадают от эпидемии COVID-19 (например, в секторе услуг), либо пострадают от нарушения их цепочки поставок, роста безработицы и сокращения спроса (субъекты малого и среднего предпринимательства).

\section{Выводы}

Содержательное наполнение парадигмы «позитивногонегативного эффекта» влияния на конкуренцию и получения соизмеримых выгод обществом (экономический

22 Jenny Frédéric. Competition law and health crisis-04 May 2020 // Competition law and health crisis. On-Topic - Concurrences $N^{\circ} 2-2020$ : www.concurrences.com 107 (Дата обращения: 12.05.2020).

23 Федеральный закон от 24.04.2020 № 124-Ф3 «0 внесении изменений в отдельные законодательные акты Российской Федерации по вопросам обеспечения устойчивого развития экономики в условиях ухудшения ситуации в связи с распространением новой коронавирусной инфекции». http://www.kremlin.ru/acts/ news/63261 (Дата обращения: 20.05.2020); Правительство выделило более 81,1 млрд рублей на помощь малым и средним предприятиям из пострадавших отраслей; Утверждена субсидия для запуска программы льготного кредитования по ставке $2 \%$. http://government.ru/news/ (Дата обращения: 20.05.2020).

24 Меры ФАС России в связи с пандемией COVID-19. https://fas.gov. ru/pages/mery-v-svjazi-s-pandemiej-covid-2019 (Дата обращения: 13.05.2020). 
Пандемия COVID-19 как вызов для экономической конкуренции...

прогресс, совершенствование производства, повышение конкурентоспособности и др.) на ближайшие годы станет своеобразным мейнстримом оценки допустимости со стороны антимонопольного ведомства принимаемых компаниями решений в формировании их бизнес-стратегий и управленческого администрирования, равно как и заключаемых компаниями соглашений.

В связи с этим наиболее важными направлениями поддержки со стороны ФАС России должны стать в первую очередь детально разработанные положения ст. 13 Закона «О защите конкуренции» и практические рекомендации по их применению, что, соответственно, требует принципиально иного уровня экономического анализа по отдельным категориям дел и сделок с целью правильного и обоснованного взвешивания эффектов.

Это особенно важно для потребителей, а также для новых и малых предприятий, которые чаще всего страдают от кризиса. Как отметил Ф. Жанни, «ряд экономистов убедительно доказывают, что рыночные силы сами по себе недостаточны для перераспределения ресурсов на уровне и скорости, необходимых для решения этих задач. Это означает, что даже если конкуренция необходима, ее недостаточно для решения тех задач, с которыми мы сталкиваемся в XXI веке. Политика в области конкуренции должна быть лучше интегрирована в более широкий контекст взаимодополняющей экономической политики» ${ }^{25}$.

В ближайшем будущем поощрение конкуренции, особенно в России, возможно, будет столь же важной экономической задачей, как это было в начале 1990-х гг., когда необходимо было восстановить на новой рыночной основе полностью разорванные производственные цепочки. Поддержание конкуренции в долгосрочной перспективе имеет важное значение для функционирования рынков, благосостояния потребителей, обеспечения инноваций, занятости и экономического роста. Как и в условиях предыдущих экономических кризисов, усилия антимонопольного органа России и политика по продвижению и защите конкуренции будут играть решающую роль в управлении последствиями кризиса и в создании наилучших условий для восстановления экономики. Представляется, что именно эти предпосылки должны лечь в основу содержания нового Национального плана развития конкуренции на 2021-2025 гг.

\section{Литература}

1. Официальные материалы Секретариата Конференции ООН по торговле и развитию (ЮНКТАД) [Электронный ресурс] https://unctad.org/en/pages/ newsdetails.aspx?OriginalVersionlD=2325 (Дата обращения: 10.05.2020).

25 Concurrences' Special On-Topic on Competition Law and Health crisis, with contributions from Frédéric Jenny, Marcel Boyer, Christophe Bovet. https://www.concurrences.com/en/review/issues/ no-2-2020/on-topic/competition-law-and-health-crisis-en (Дата обращения: 27.04.2020).
2. Официальные материалы Генеральной дирекции по конкуренции Еврокомиссии [Электронный ресурс] https://ec.europa.eu/competition/index_en.htm (Дата обращения: 10.05.2020).

3. Официальные материалы Организации экономического сотрудничества и развития (ОЭСР) [Электронный ресурс] https://www.oecd.org/competition/ competition-policy-responses-to-covid-19.htm (Дата обращения: 10.05.2020).

4. Официальные материалы Международной конкурентной сети (ICN) [Электронныйресурс] https://www. internationalcompetitionnetwork.org/wp-content/ uploads/2020/04/SG-Covid19Statement (Дата обращения: 10.05.2020).

5. Глава ФАС России Игорь Артемьев о ситуации на рынке лекарственных препаратов и медизделий: Брифинг в пресс-центре Правительства Российской Федерации. https://fas.gov.ru/news/29560 https://fas. gov.ru/news/29619 (Дата обращения:13.05.2020).

6. Statement of Igor Artemiev, Head of the FAS Russia, to the international competition community on COVID-19 [Электронный ресурс] http://en.fas.gov.ru/presscenter/news/detail.html?id=54878 (Дата обращения: 13.05.2020).

7. ЦЦганов А. Пандемия - новый вызов для всех конкурентных ведомств мира. https://fas.gov.ru/news/29781 (Дата обращения: 15.05.2020).

8. Меры ФАС России в связи с пандемией COVID-19. https://fas.gov.ru/pages/mery-v-svjazi-s-pandemiejcovid-2019 (Дата обращения:13.05.2020).

9. Horna P.M. A global overview of the impact of COVID-19 on competition policies in key sectors // Competition law and health crisis. On-Topic I Concurrences N²-2020: www.concurrences.com (Дата обращения:12.05.2020).

10. Price-Gouging-Letters-3.25.20. https://ago.vermont. gov/wp-content/uploads/2020/03/Price-GougingLetters-3.25.20.pdf (Дата обращения:17.05.2020).

11. Concurrences' Special On-Topic on Competition Law and Health crisis, with contributions from Frédéric Jenny, Marcel Boyer, Christophe Bovet. https://www. concurrences.com/en/review/issues/no-2-2020/ontopic/competition-law-and-health-crisis-en (Дата обращения: 27.04.2020).

12. Jenny Frédéric. Competition law and health crisis-04 May 2020 [Электронный ресурс] // Competition law and health crisis. On-Topic - Concurrences $N^{\circ} 2-2020$ : www.concurrences.com 107 (Дата обращения: 12.05.2020).

\section{Сведения об авторе}

Князева Ирина Владимировна: доктор экономических наук, профессор, РАНХиГС (Сибирский институт управления - филиал), профессор, руководитель Центра исследования конкуренции и экономики

Контактная информация:

E-mail: irknyazeva @yandex.ru 